\title{
FAKTOR-FAKTOR YANG BERHUBUNGAN DENGAN PEMBERIAN MP-ASI DINI DI WILAYAH KERJA UPTD PUSKESMAS SINDANGLAUT KECAMATAN LEMAHABANG KABUPATEN CIREBON
}

\author{
Nina Nirmaya Mariani ${ }^{1}$, Hendi Hendarman ${ }^{2}$, Giti Sri Nita ${ }^{3}$ \\ ${ }^{1,3}$ Program Studi Kebidanan Cirebon, Poltekes Tasikmalaya \\ ${ }^{2}$ Program Studi Gizi Cirebon, Poltekes Tasikmalaya \\ Email: nina.nirmaya.mariani@gmail.com
}

\begin{abstract}
Related Factors to Premature Complementary Feeding in the Working Area of UPTD Puskesmas Sindanglaut, Lemahabang Subdistrict Cirebon Regency. The incidence of premature complementary feeding is still high in Indonesia. More than 50\% of infants in Indonesia get complementary feeding. This condition is also seen in people in the working area of UPTD Puskesmas Sindanglaut that high incidence of the premature complementary feeding. This study was to determine the factors that related to premature complementary feeding in the working area of UPTD Puskesmas Sindanglaut, Lemahabang Subdistrict Cirebon Regency, in December 2014 to January 2015. This study used cross sectional analytic approach, sampling techniques were sistematyc random sampling with 204 respondents as samples (mothers with babies aged 6-12 month). Data were analyzed by chi square test $(\alpha=0.05)$. The results showed that majority of $\mathcal{2}$ parity were 146 respondents $(71.6 \%)$, the level of knowledge of mothers were good (140 respondents, 68.6\%), and the majority of respondents get family support (133 respondents, $65.2 \%$ ). Bivariate analysis showed that parity and family support related to premature complementary feeding, while knowledge does not affect the premature complementary feeding.
\end{abstract}

Keywords: Parity, Knowledge, Family support, Premature complementary feeding

\begin{abstract}
Abstrak: Faktor-faktor yang Berhubungan dengan Pemberian MP-ASI Dini di Wilayah Kerja UPTD Puskesmas Sindanglaut Kecamatan Lemahabang Kabupaten Cirebon. Angka kejadian MP-ASI dini di Indonesia masih tinggi. Rata-rata lebih dari 50\% bayi di Indonesia mendapatkan pendamping ASI. Kondisi tersebut juga terlihat pada masyarakat di wilayah kerja UPTD Puskesmas Sindanglaut yang masih tinggi pemberian MP-ASI dini. Tujuan penelitian adalah untuk mengetahui faktor-faktor yang behubungan dengan pemberian MP-ASI dini di wilayah kerja UPTD Puskesmas Sindanglaut Kecamatan Lemahabang Kabupaten Cirebon Periode Desember 2014 s.d Januari 2015. Metode yang digunakan ialah analitik dengan pendekatan cross sectional, teknik sampel adalah sistematyc random sampling, dengan jumlah sampel 204 responden (ibu yang memiliki bayi 6-12bulan). Analisis data dengan uji chi square, tingkat kesalahan $5 \%$ atau $\alpha=0,05$. Didapatkan hasil mayoritas paritas $\mathcal{S}$ sebanyak 146 responden (71,6\%), tingkat pengetahuan ibu mayoritas baik sebanyak 140 responden(68,6\%), dan mayoritas responden mendapatkan dukungan keluarga sebanyak 133 responden $(65,2 \%)$. Berdasarkan analisis bivariat menunjukkan adanya hubungan antara paritas, dukungan keluarga terhadap pemberian MP-ASI dini, dan pengetahuan tidak mempengaruhi pemberian MP-ASI dini. Diharapkan adanya kerjasama dengan kader, perangkat desa, tokoh masyarakat, guna memberikan penyuluhan untuk meningkatkan terealisasinya pemberian makanan pendamping ASI tepat sesuai waktunya.
\end{abstract}

Kata kunci: Paritas, Pengetahuan, Dukungan keluarga, MP-ASI dini

Kemajuan suatu bangsa dipengaruhi dan ditentukan dari tingkat kesehatan masyarakat, yang salah satunya bisa dilihat dari status gizi manusianya .Salah satu upaya untuk mencapai terpenuhinya status gizi dimulai dengan mewujudkan periode emas yaitu pada masa bayi dan anak-anak, dimana pada masa tersebut merupakan masa yang membutuhkan asupan gizi yang sesuai sehingga diharapkan tumbuh dan berkembang secara optimal. Untuk mencapai hal tersebut, maka Global Strategy for Infant and Young Child Feeding, World Health Organization (WHO) dan UNICEF merekomendasikan empat hal penting yang harus dilakukan yaitu, pertama memberikan air susu ibu kepada bayi segera dalam waktu 30 menit 
setelah bayi lahir, kedua memberikan hanya air susu ibu (ASI) saja atau pemberian ASI secara eksklusif sejak lahir sampai bayi berusia 6 bulan, ketiga memberikan makanan pendamping air susu ibu (MP-ASI) sejak bayi berusia 6 bulan sampai 24 bulan dan keempat meneruskan pemberian ASI sampai anak berusia 24 bulan atau lebih.

Periode emas yang telah dijelaskan tersebut pun tidak hanya dipengaruhi oleh asupan gizi saja karena sudah sejak lama disadari bahwa faktor perilaku dan sosial budaya juga sangat berpengaruh terhadap terhadap masalah gizi. Perilaku negatif berupa pantangan makanan serta pemberian makanan sebelum usianya masih ditemui di beberapa daerah, terutama daerah yang miskin akan informasi dan kental akan mitosmitos. Salah satu perilaku negatif tersebut adalah pemberian Makanan Pendamping ASI (MP-ASI) terlalu dini.

MP-ASI adalah makanan atau minuman yang mengandung zat gizi, di berikan kepada bayi atau anak usia 6-24 bulan guna memenuhi kebutuhan gizi selain dari ASI (Depkes, 2006). MP-ASI merupakan makanan peralihan dari ASI ke makanan keluarga, pengenalan dan pemberian MP-ASI harus dilakukan secara bertahap baik bentuk maupun jumlah.

Gizi memegang peranan penting dalam siklus hidup manusia. Kekurangan gizi pada ibu hamil dapat menyebabkan Bayi Berat Lahir Rendah (BBLR) dan dapat pula menyebabkan penurunan tingkat kecerdasan. Pada bayi dan anak, kekurangan gizi akan menimbulkan gangguan pertumbuhan dan perkembangan yang apabila tidak diatasi secara dini dapat berlanjut hingga dewasa. Namun kenyataan tersebut terkadang menimbulkan kesalah pahaman yaitu dengan alasan memenuhi kebutuhan gizi bayi, maka dilakukan pemberian MP-ASI yang terlalu dini. Pemberian MP-ASI terlalu dini disebabkan kurangnya pengalaman pada ibu menyusui yang beranggapan bahwa bayinya tidak akan kenyang jika hanya mengkonsumsi ASI saja.

Fenomena pemberian MP-ASI terlalu dini pun memiliki persentase yang cukup tinggi terutama di Indonesia, berdasarkan SDKI tahun 2012 bayi 4-5 bulan mendapatkan makanan pendamping ASI secara dini sebesar 57\%, 8\% diberi susu lain dan $8 \%$ diberi air putih. Selain itu terbukti dengan hasil penelitian yang dilakukan oleh Irawati (2007) pada Pusat Pelatihan dan Pengembangan Gizi dan Makanan Departemen Kesehatan, yang menyatakan bahwa lebih dari $50 \%$ bayi Indonesia mendapatkan makanan pendamping ASI sebelum usia 1 bulan. Padahal seperti yang kita ketahui bahwa pemberian MP-
ASI terlalu dini akan memeberikan dampak buruk yang salah satunya adalah adanya gangguan pencernaan pada bayi seperti diare, muntah dan sulit buang air besar (Cott, 2003). Di samping itu pemberian makanan pendamping ASI juga akan mempengaruhi tingkat kecerdasan otak setelah dewasa seperti memicu terjadinya penyakit obesitas, hipertensi, dan penyakit jantung koroner (Nadesul, 2005).

Pemberian MP-ASI haruslah

memperhatikan beberapa hal seperti, MP-ASI tersebut haruslah mudah untuk dicerna bayi, harus disesuaikan dengan usia dan kebutuhan bayi, harus mengandung kalori dan mikronutrien yang cukup, ketetapan waktu pemberian, frekuensi, jenis, jumlah makanan, dan cara pembuatannya (Depkes RI, 2006).

Banyak faktor yang mempengaruhi dalam pemberian makanan pendamping ASI terlalu dini, yang pertama adalah adanya faktor paritas ibu karena hasil penelitian yang dilakukan oleh Kardiani (2012) di Cibolerang Kecamatan Jatiwangi, berdasarkan paritas yang memberikan MP-ASI terlalu dini terbanyak adalah pada jumlah paritas 1 sebesar 46\% (30 orang) karena para ibu tersebut beranggapan bahwa bayinya tidak kenyang jika hanya mengkonsumsi ASI saja. Faktor kedua, adanya kebiasaan masyarakat yang ada di daerah tersebut karena tak dapat dipungkiri bahwa adat istiadat masyarakat yang telah ada sejak zaman dahulu juga mempengaruhi tingginya pemberian MP-ASI yang terlalu dini. Ketiga, adanya faktor pengetahuan yang dimiliki ibu dan terakhir adalah adanya faktor dukungan keluarga. Peran keluarga dalam pemberian MPASI $>6$ bulan sangat dibutuhkan, terlebih kultur masyarakat Indonesia yang masih bersifat kolektif yaitu keluarga berperan dalam pola pengurusan anak khususnya dalam pengurusan bayi.

Berdasarkan data yang diperoleh dari studi pendahuluan yang dilakukan di wilayah kerja UPTD Puskesmas Sindanglaut terdapat angka pemberian MP-ASI yang cukup tinggi. Pada tahun 2011 angka pemberian MP-ASI dini di UPTD Puskesmas Sindanglaut sebesar 74\%, pada tahun 2012 sebesar 63\%, pada tahun 2013 sebesar 44\%, dan pada tahun 2014 tercatat sebesar $65 \%$. Keadaan tersebut menggambarkan bagaimana adanya peningkatan dari setiap tahunnya dalam pemberian MP-ASI dini di wilayah kerja UPTD Puskesmas Sindanglaut.

Tujuan penelitian ini adalah untuk mengetahui faktor-faktor yang berhubungan dengan pemberian MP-ASI dini di wilayah kerja UPTD Puskesmas Sindanglaut Kecamatan 
Lemahabang Kabupaten Cirebon periode Desember 2014 s.d Januari 2015.

\section{METODE PENELITIAN}

Penelitian ini menggunakan metode analitik dengan pendekatan "cross sectional" yaitu suatu penelitian (survei) untuk mempelajari dinamika korelasi antara faktor-faktor risiko dengan efek, dengan cara pendekatan, observasi, atau pengumpulan data sekaligus pada suatu saat (point time approach) (Notoatmojo, 2012). Penelitian ini dilaksanakan di wilayah kerja UPTD Puskesmas Sindanglaut Kecamatan Lemahabang Kabupaten Cirebon dan waktu penelitian dilakukan dari bulan Desember 2014 s.d Januari 2015.

Populasi dalam penelitian ini adalah seluruh ibu yang mempunyai bayi 6-12 bulan tahun 2014 yaitu sebanyak 415 orang. Pemilihan subjek ibu dengan bayi berusia 6-12 bulan dengan pertimbangan daya ingat ibu tentang proses menyusui masih baik, hal tersebut dimaksudkan untuk menghindari bias informasi. Sampel yang digunakan dalam penelitian ini adalah ibu yang mempunyai bayi 6-12 bulan di wilayah kerja UPTD Puskesmas Sindanglaut yaitu sebanyak 204 orang. Cara pengambilan sampel pada penelitian ini menggunakan sistematyc random sampling.

Pengumpulan data mengunakan kuesioner yang telah dilakukan uji validitas dan reliabilitas sebelumnya. Kuesioner tersebut dalam bentuk clossed ended (pertanyaan tertutup). Kuesioner yang dibuat untuk mengukur tingkat pengetahuan ibu mengenai MP-ASI dan dukungan keluarga kepada ibu untuk memberikan MP-ASI dini. Penilaian pada variabel pengetahuan, dengan menggunakan skala Guttman. Hasil ukur pengetahuan dibagi menjadi 2 kategori yaitu baik dan buruk. Dikatakan baik jika nilai skor $\geq$ ratarata dan dikatakan buruk jika nilai skor < ratarata. Untuk hasil ukur dukungan keluarga dibagi menjadi 2 kategori yaitu ada dukungan dan tidak ada dukungan. Dikatakan ada dukungan jika nilai skor $\geq$ rata-rata dan dikatakan tidak ada dukungan jika nilai skor < rata-rata.

Analisis data yang digunakan dalam penelitian ini adalah analisis univariat. Adapun analisis univariat dalam penelitian ini dibuat dalam bentuk tabel frekuensi (prosentase). Analisis bivariat yang dilakukan terhadap dua variabel yang diduga berhubungan atau berkolerasi. Uji statistik yang digunakan yaitu chi square untuk melihat hubungan 2 variabel tersebut bermakna atau tidak bermakna
(Notoatmodjo, 2012). Tingkat kepercayaan $\alpha=0,05$. Metode pengujian hipotesis dengan menggunakan perangkat lunak SPSS 18. Adapun interpretasi dari analisis yang dilakukan adalah bila nilai $p$-value $₫, 05$, maka $\mathrm{H}_{0}$ ditolak yang berarti terdapat hubungan yang bermakna antara variabel independen dan variabel dependen. Tetapi bila nilai $p$-value $>0,05$, maka $\mathrm{H}_{0}$ diterima yang berarti tidak terdapat hubungan yang bermakna antara variabel independen dan variabel dependen.

\section{HASIL}

Hasil penelitian pada analisis univariat yang dilakukan di wilayah kerja UPTD Puskesmas Sindanglaut Kecamatan Lemahabang Kabupaten Cirebon dari bulan Desember 2014 s.d Januari 2015 dengan jumlah responden sebanyak 204 orang adalah sebagai berikut:

Tabel 1. Distribusi frekuensi paritas ibu, pengetahuan ibu, dukungan keluarga dan pemberian MP-ASI dini.

\begin{tabular}{lcc}
\hline \multirow{2}{*}{ Variabel } & \multicolumn{2}{c}{ Total } \\
\cline { 2 - 3 } & n & \% \\
\hline $\begin{array}{l}\text { Paritas ibu } \\
\leq 2\end{array}$ & 146 & 71,6 \\
$>2$ & 58 & 28,4 \\
\hline Pengetahuan ibu & & \\
Baik & 140 & 68,6 \\
Buruk & 64 & 31,4 \\
\hline Dukungan keluarga & & \\
Ada & 133 & 65,2 \\
Tidak ada & 71 & 34,8 \\
\hline Pemberian MP-ASI Dini & & \\
Ya & 136 & 66,7 \\
Tidak & 68 & 33,3 \\
\hline
\end{tabular}

Berdasarkan tabel 1 menunjukkan bahwa mayoritas paritas ibu yang memberikan MP ASI dini $\leq 2$ yaitu $71,6 \%$, mayoritas memiliki pengetahuan yang baik sebesar $68,6 \%$, mayoritas responden mendapatkan dukungan keluarga terhadap pemberian MP ASI dini sebesar 65,2\% dan Mayoritas ibu memberikan MP ASI dini sebesar $66,7 \%$.

Adapun bentuk analisis bivariat dari hasil penelitian yang dilakukan di wilayah kerja UPTD Puskesmas Sindanglaut Kecamatan Lemahabang Kabupaten Cirebon adalah sebagai berikut: 
Tabel 2. Hubungan antara paritas ibu, pengetahuan ibu dan dukungan keluarga dengan Pemberian MP ASI Dini.

\begin{tabular}{|c|c|c|c|c|c|c|c|}
\hline \multirow{3}{*}{ Variabel } & \multicolumn{4}{|c|}{$\begin{array}{l}\text { Pemberian MP-ASI } \\
\text { dini }\end{array}$} & \multirow{2}{*}{\multicolumn{2}{|c|}{ Total }} & \multirow{3}{*}{$\begin{array}{c}p- \\
\text { value }\end{array}$} \\
\hline & \multicolumn{2}{|c|}{$\mathrm{Ya}$} & \multicolumn{2}{|c|}{ Tidak } & & & \\
\hline & $\mathrm{n}$ & $\%$ & $\mathrm{n}$ & $\%$ & $\mathrm{n}$ & $\%$ & \\
\hline \multicolumn{8}{|l|}{ Paritas ibu } \\
\hline$\leq 2$ & 89 & 61 & 57 & 39 & 146 & 100 & \multirow[t]{2}{*}{0,008} \\
\hline$>2$ & 47 & 19 & 11 & 81 & 58 & 100 & \\
\hline \multicolumn{7}{|c|}{$\begin{array}{l}\text { Pengetahuan } \\
\text { ibu }\end{array}$} & \multirow{3}{*}{1,000} \\
\hline Baik & 93 & 66,4 & 47 & 33,6 & 140 & 100 & \\
\hline Buruk & 43 & 67,2 & 21 & 32,8 & 64 & 100 & \\
\hline \multicolumn{7}{|l|}{ Dukungan } & \multirow{3}{*}{0,000} \\
\hline Ada & 130 & 97,7 & 3 & 2,3 & 133 & 100 & \\
\hline Tidak ada & 6 & 8,5 & 65 & 91,5 & 71 & 100 & \\
\hline
\end{tabular}

Berdasarkan hasil uji statistik didapatkan 2 variabel yang terdapat hubungan yang bermakna yaitu variabel paritas ibu $(p$-value $=0,008)$ dan variabel dukungan keluarga $(p$-value $=0,000)$. Sedangkan variabel yang tidak terdapat hubungan yaitu variabel pengetahuan ibu ( $p$-value $=1,000$ ).

\section{PEMBAHASAN}

\section{Paritas Ibu}

Hasil penelitian yang dilakukan di wilayah kerja UPTD Puskesmas Sindanglaut Kecamatan Lemahabang Kabupaten Cirebon periode Desember 2014 s.d Januari 2015 mengenai faktor-faktor yang berhubungan dengan pemberian MP-ASI dini, kepada 204 responden, didapatkan hasil yaitu terdapat hubungan yang bermakna antara paritas ibu dengan pemberian MP-ASI dini. Hasil penelitian ini sesuai dengan teori yang di kemukakan oleh Wiknjosastro (2007), mengemukakan paritas >3 cenderung memiliki waktu lebih untuk mempelajari sesuatu sehingga memiliki pengetahuan yang lebih tinggi. Emi Puji Rahayu (2007) juga mengemukakan ibu yang memiliki paritas $>4$ akan memiliki pengetahuan yang lebih baik mengenai pengetahuan ASI Eksklusif.

Menurut teori World Health Organization (WHO) yang dikutip oleh Notoatmodjo (2007), salah satu bentuk objek kesehatan dapat dijabarkan oleh pengetahuan yang diperoleh dari pengalaman sendiri (Wawan \& Dewi M., 2010).

Dari teori tersebut peneliti berpendapat semakin banyak pengalaman sendiri dalam hal ini paritas yang di maksud maka risiko yang akan terjadipun akan semakin tinggi terhadap pemberian makanan pendamping ASI secara dini.
Sebaliknya bagi mereka yang berparitas rendah maka risiko pemberian MP-ASI pun akan rendah.

Hasil uji hubungan yang dilakukan peneliti ini juga sejalan dengan penelitian yang dilakukan oleh Ginting (2009) mengenai pengaruh karakteristik, faktor internal dan eksternal ibu terhadap pemberian MP-ASI dini pada bayi usia $<6$ bulan di wilayah kerja Puskesmas Barusjahe Provinsi Sumatera Utara. Berdasarkan uji chi square didapat $p$-value $=0,013$ artinya terdapat hubungan antara paritas terhadap pemberian MPASI dini.

Penelitian Kardiani (2012) mengenai gambaran karakteristik dan pengetahuan ibu yang mempengaruhi pemberian makanan pendamping ASI terlalu dini di desa Cibolerang Kecamatan Jatiwangi Kabupaten Majalengka, berdasarkan uji chi square didapat $p$-value $=0,015$ artinya terdapat hubungan antara paritas terhadap pemberian MP-ASI dini.

Disamping itu faktor-faktor lain juga dapat mempengaruhi seperti yang di kemukakan oleh Sutayani(2012) yaitu pemberian ASI atau MPASI tak lepas dari tatanan budaya, dalam konteks budaya dituturkan berbagai gambaran perilaku ibu menyusui. Perilaku dibentuk oleh kebiasaan yang bisa diwarnai adat, tatanan norma yang berlaku di masyarakat dan kepercayaan. Perilaku umumnya tidak terjadi secara tiba-tiba. Perilaku adalah hasil dari proses yang berlangsung selama masa perkembangan. Setiap orang selalu terpapar dan tersentuh oleh kebiasaaan di lingkungannya serta pengaruh dari masyarakat, baik secara langsung maupun tidak langsung.

Paritas yang rendah $(\leq 2)$ cenderung untuk memberikan MP-ASI dini disebabkan karena minimnya pengetahuan dan pengalaman yang dimiliki dalam memberikan MP-ASI. Pemberian informasi yang lebih dini diberikan pada paritas rendah agar melakukan pemberian MP-ASI sesuai dengan ketentuan yang seharusnya sehingga bayi dapat tumbuh kembang secara normal.

\section{Pengetahuan Ibu}

Hasil penelitian yang dilakukan di wilayah kerja UPTD Puskesmas Sindanglaut Kecamatan Lemahabang Kabupaten Cirebon terhadap 204 responden, didapatkan hasil yaitu tidak terdapat hubungan yang bermakna antara pengetahuan ibu dengan pemberian MP-ASI dini.

Hasil penelitian ini juga didukung oleh penelitian Asdan Padang (2008) mengenai analisa faktor-faktor yang mempengaruhi ibu dalam pemberian MP-ASI dini di Kecamatan Pandan Kabupaten Tapanuli Tengah tahun 2007 
diperoleh nilai $p$-value $=0,610$ yang lebih besar dari $a=0,05$ artinya tidak terdapat hubungan yang signifikan antara pengetahuan terhadap kejadian pemberian MP-ASI dini.

Penelitian ini sesuai dengan teori Toruntju (2005) untuk berhasilnya seseorang ibu dalam memberikan ASI eksklusif tidak terlepas dari pengetahuan ibu tentang ASI eksklusif karena dengan pengetahuan, perilaku dapat diarahkan ke hal yang lebih baik. Beberapa hal yang mempengaruhi pengetahuan adalah pendidikan, pengalaman, budaya, kepercayaan, faktor sosial ekonomi dan kesempatan dalam mendapatkan informasi.

Dari teori diatas bahwa sama halnya dengan ASI Eksklusif, MP-ASI pun demikian, ketidak berhasilan ASI eksklusif maka akan membuat anak mendapatkan MP-ASI secara dini. Pengetahuan yang baik tidak menjamin ibu akan memberikan MP-ASI sesuai waktunya, karena dilihat dari teori diatas pengetahuan di pengaruhi oleh pendidikan, pengalaman, budaya, kepercayaan, faktor sosial ekonomi dan kesempatan dalam mendapatkan informasi.

Hal tersebut diatas juga sesuai dengan teori Lawrence Green (1993) pada penelitian Asdan, juga mengatakan pengetahuan merupakan bentuk dari perilaku yang diamati dari sikap, tindakan dan perilaku tersebut bersifat potensial yakni motivasi dan persepsi. Perilaku sendiri salah satunya dibentuk dari faktor kepercayaan dan keyakinan. Kepercayaan merupakan tahap selanjutnya dari perilaku, bahwa jika pengetahuan baik dan sikapnya sudah di wujudkan dalam bentuk kepercayaan maka biasanya perilaku lebih sulit untuk diubah.

Hasil penelitian ini sesuai dengan teori Lawrence Green, bahwa ketika responden memiliki pengetahuan yang baik akan tetapi sikap responden sudah diwujudkan dalam bentuk kepercayaan mengenai pemberian MP-ASI secara dini karena beranggapan bayi yang mendapatkan ASI saja tidak kenyang, dan dengan adanyanya adat kebiasaan yang berkembang di masyarakat mengenai pemberian makanan pendamping ASI kepada bayi pada usia dibawah $<6$ bulan, maka pengetuan yang baik tidak selalu menghasilkan perilaku yang baik.

Kondisi tersebut sesuai dengan teori yang mendukung hal tersebut yang dikemukakan oleh Tri Prasetyo (2004) yaitu manusia hidupnya di masyarakat, hal ini bukan hanya sekedar ketentuan semata-mata, melainkan mempunyai arti yang lebih dalam, yaitu bahwa hidup bermasyarakat itu adalah rukun bagi manusia agar benar-benar dapat mengembangkan budayanya dan mencapai kebudayaan.
Pengetahuan tidak menjamin ibu akan memberikan MP-ASI, karena banyak faktor yang mempengaruhinya diantaranya yaitu pendidikan, pengalaman, budaya, kepercayaan, faktor sosial ekonomi dan kesempatan dalam mendapatkan informasi. Petugas kesehatan harus terus memberikan pengetahuan tidak hanya kepada ibu yang punya bayi saja akan tetapi diberikan kepada ibu hamil agar lebih mempersiapkan diri menjadi ibu. Selain itu harus ada kerjasama lintas sektoral dalam pemberian informasi kepada masyarakat.

\section{Dukungan Keluarga}

Hasil penelitian yang dilakukan di wilayah kerja UPTD Puskesmas Sindanglaut Kecamatan Lemahabang Kabupaten Cirebon terhadap 204 responden, didapatkan hasil yaitu terdapat hubungan yang bermakna antara dukungan keluarga dengan pemberian MP-ASI dini.

Hasil penelitian ini didukung oleh penelitian Asdan Padang (2008) mengenai analisa faktor-faktor yang mempengaruhi ibu dalam pemberian MP-ASI dini di Kecamatan Pandan Kabupaten Tapanuli Tengah tahun 2007 diperoleh nilai $p$-value $=0,019$ yang lebih kecil dari $a=0,05$ artinya terdapat hubungan yang signifikan antara dukungan keluarga terhadap kejadian pemberian MP-ASI dini.

Hasil penelitian lain dilakukan oleh Ginting (2009) mengenai pengaruh karakteristik, faktor internal dan eksternal ibu terhadap pemberian MP-ASI dini pada bayi usia $<6$ bulan di wilayah kerja puskesmas Barusjahe Provinsi Sumatera Utara. Berdasarkan uji chi square didapat $p$-value $=0,001$ artinya terdapat hubungan antara dukungan keluarga terhadap pemberian MP-ASI dini.

Penelitian ini sesuai dengan teori yang di kemukakan oleh Kelly (2007) bahwa dukungan dari keluarga memiliki dampak yang cukup besar terhadap keputusan seseorang ibu untuk terus menyusui. Meskipun menyusui bayi adalah hal yang paling alami di dunia, tetapi komitmen dan usaha keras harus tetap dimiliki oleh ibu karena menyusui tidak selalu mudah terutama jika seorang ibu mengalami masalah, merasa sangat lelah, dan merasa kurang waktu karena bekerja atau memiliki kesibukan diluar rumah.

Dian (2000) juga mengemukakan para ibu yang menyusui membutuhkan dukungan emosinal dan informasi dari orang-orang terdekat sehingga ibu lebih mungkin untuk merasa yakin tentang kemampuan mereka untuk menyusui atau tidak memberikan MP-ASI dini. 
Dari teori Kelly (2007) dan Dian (2000) yang telah dikemukakan diatas peneliti berpendapat sama halnya dengan ASI eksklusif, MP-ASI dinipun dipengaruhi oleh dukungan keluarga. Dalam hal ini erat kaitannya dengan ASI Eksklusif, jika keluarga tidak memberikan dukungan terhadap pemberian ASI maka MPASI dini yang akan terjadi.

Berdasarkan hal di atas tersebut maka semakin besarnya dukungan keluarga terhadap pemberian MP-ASI dini maka kejadian MP-ASI akan semakin tinggi. begitu juga sebaliknya jika dukungan keluarga rendah terhadap pemberian MP-ASI dini, maka kejadian pemberian MP-ASI dini pun akan rendah.

Sesuai dengan teori Zainuddin (2007) mengemukakan dukungan keluarga merupakan bantuan yang nyata atau tingkah laku yang diberikan oleh orang-orang akrab dengan subjek di dalam lingkungan sosialnya atau yang berupa kehadiran dan hal yang dapat memberikan keuntungan emosional atau pengaruh pada tingkah laku penerimaannya. Dalam hal ini orang yang merasa memperoleh dukungan sosial, secara emosinal merasa lega diperhatikan, mendapatkan saran atau kesan yang menyenangkan pada dirinya.

Dari teori Zainuddin (2007) tersebut peneliti berpendapat dukungan keluarga terhadap pemberian MP-ASI sangat berpengaruh sesuai dengan hasil penelitian peneliti. Melakukan pemberian makanan pendamping ASI tidak lepas dari peran dukungan keluarga. Keluarga yang memberikan fasilitas bantuan yang nyata atau tingkah laku terhadap pemberian MP-ASI, maka ibu akan menerima perlakuan tersebut karena di anggap perlakuan itu berupa bentuk nyata dari kepedulian terhadap anggota keluarga. Oleh sebab itu, dukungan dari keluarga tersebut dapat memudahkan ibu dalam pemberian makanan pendamping pada anaknya karena ibu merasa terfasilitasi.

Selain hal diatas kultur masyarakat Indonesia yang masih bersifat kolektif, yaitu keluarga berperan dalam pola pengurusan anak khususnya dalam pengurusan bayi. Dalam keluarga yang bersifat paternalistik, keluarga yang dimaksud bertanggungjawab dalam pengurusan bayi adalah para perempuan dari anggota keluarga yang memiliki bayi (Asdan, 2008).
Kurangnya dukungan keluarga terhadap pemberian ASI Eksklusif berdampak pada pemberian MP-ASI pada bayi, hal ini dikarenakan kurangnya anggota keluarga tentang MP-ASI sehingga menyebabkan kurangnya motivasi atau dorongan yang diberikan keluarga terhadap ibu untuk pemberian ASI Eksklusif. Sebaiknya ibu yang mendapatkan motivasi atau dukungan dari keluarga secara psikologis akan memiliki semangat dalam memberikan ASI Eksklusif pada bayinya serta dapat merespon syaraf-syaraf yang dapat memperlancar produksi ASI.

\section{SIMPULAN}

Berdasarkan hasil penelitian dapat diambil kesimpulan sebagai berikut :

1. Sebagian besar Ibu bayi 6-12 bulan di wilayah kerja UPTD Puskesmas Sindanglaut periode Desember 2014 s.d Januari 2015 mayoritas mempunyai paritas $\mathcal{s}$, memiliki tingkat pengetahuan yang baik, memiliki dukungan keluarga terhadap pemberian MP-ASI dini dan memberikan MP-ASI secara dini.

2. Terdapat hubungan antara paritas terhadap kejadian pemberian MP-ASI dini di wilayah kerja UPTD Puskesmas Sindanglaut periode Desember 2014 s.d Januari 2015.

3. Tidak terdapat hubungan antara pengetahuan terhadap kejadian pemberian MP-ASI dini di wilayah kerja UPTD Puskesmas Sindanglaut periode Desember 2014 s.d Januari 2015.

4. Terdapat hubungan antara dukungan keluarga terhadap kejadian pemberian MP-ASI dini di wilayah kerja UPTD Puskesmas Sindanglaut periode Desember 2014 s.d Januari 2015.

\section{SARAN}

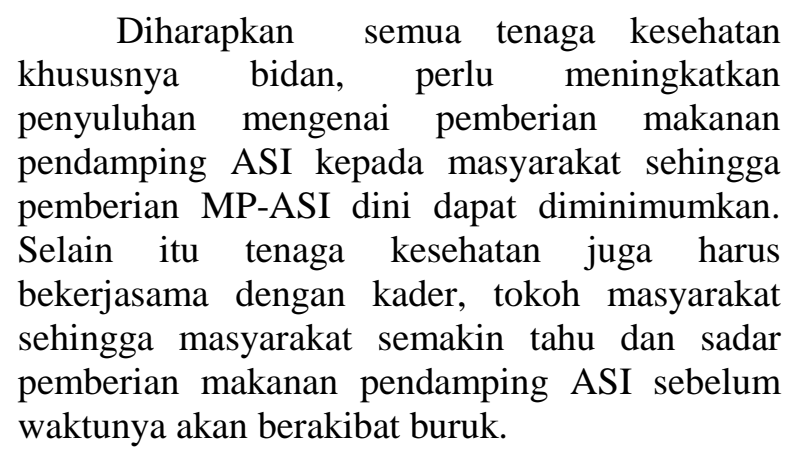




\section{DAFTAR PUSTAKA}

A. Wawan dan Dewi M. 2010. Teori \& Pengukuran Pengetahuan Sikap dan Perilaku Manusia. Yogyakarta: Nuha Medika.

Cott, P.W. 2003. Seri Budaya Anak, Makanan Sehat untuk Bayi dan Balita. Jakarta: Dian Rakyat.

Depkes RI. 2006. Pedoman Pelaksanaan Pendistribusian dan Pengelolaan Makanan Pendamping Air Susu Ibu Tahun 2004. Jakarta: Direktorat Jenderal Gizi Masyarakat.

2006. Pedoman Umum Pemberian Makanan Pendamping ASI Lokal Tahun 2006. Jakarta: Direktorat Jenderal Bina Kesehatan Masyarakat.

Dian. 2000. Menyusui Bayi Anda. Jakarta: PT. Dian Rakyat.

Ginting, Daulat. 2009. Pengaruh Karakteristik, Faktor Internal dan Eksternal Ibu terhadap Pemberian MP-ASI Dini Pada Bayi Usia <6 Bulan di Wilayah Kerja Puskesmas Barusjahe Provinsi Sumatera Utara Tahun 2009. http://www.repository.unpad.ac.id/bitstrea m/Chapter\%20II.pdf (Diakses pada tanggal 1 Januari 2015 pukul 12.21 WIB).

Irawati, A. 2007. Stop MP-ASI Terlalu Dini. http://www.parenting.co.id./ (Diakses pada tanggal 08-12-2014 pukul 11.30 WIB).

Kelly, P. 2007. Bayi Anda Tahun Pertama: Tips Bergambar Perawatan Bayi Tahap Demi Tahap. Jakarta: Arean.
Nadesul,SH. 2005. Makanan Sehat Untuk Bayi. Jakarta: Puspa Swara.

Padang, Asdan. 2008. Analisa Faktor-Faktor yang Mempengaruhi Ibu dalam Pemberian MP-ASI Dini di Kecamatan Pandan Kabupaten Tapanuli Tengah Tahun 2007. http://www.repository.usu.ac.id/bitstream/ 123456789/37415/4/Chapter\%20II.pdf (Diakses pada 8 Desember 2014 pukul 11.08 WIB).

Notoatmodjo, S. 2012. Metodologi Penelitian Kesehatan. Jakarta: Rineka Cipta.

Sutayani, Diana Panji. 2012. Hubungan pemberian makanan Prelakteal dengan Proses menyusui di Wilayah Kerja Puskesmas Rowotwngah Kecamatan Sumber Baru, Jember. Skripsi Universitas Jember: Jember.

Toruntju, S. 2005. Faktor Sosial Ekonomi yang Berhubungan dengan Asupan Yodium Pada Ibu Hamil di DIY. Dalam Majalah Berita Kedokteran Masyarakat, IKM UGM September 2005. Yogyakarta.

Tri Prasetyo, Joko. 2004. Ilmu Budaya Dasar. Jakarta: Rineka Cipta.

UPTD Puskesmas Sindang Laut. 2014. Data Bayi, ASI Eksklusif, dan MP-ASI Dini Tahun 2011-2014.

Wiknjosastro, Hanifah. 2007. Ilmu Kebidanan. Edisi Ketiga, Cetakan Kedelapan. Yayasan Bina Pustaka Sarwono Prawirohardjo.

Zainuddin, A. 2007. Kecerdasan Emosional. Jakarta: Gramedia Pustaka Utama. 